\title{
EVALUATION OF OUT-OF-PLANE DEFORMATION OF MASONRY INFILL WALLS DUE TO IN-PLANE LOADING BY DIGITAL IMAGE CORRELATION
}

\author{
Goran Gazić ${ }^{1}$, Tihomir Dokšanović ${ }^{2}$, Hrvoje Draganić ${ }^{3}$ \\ 1 Faculty of Civil Engineering Osijek, University of Osijek, Department of Technical Mechanics, \\ Drinska 16a, HR - 31000, Osijek, Croatia. E-mail: ggazic@gfos.hr \\ 2 Faculty of Civil Engineering Osijek, University of Osijek, Department for Materials and Structures, \\ Drinska 16a, HR - 31000, Osijek, Croatia. E-mail: tdoksanovic@gfos.hr \\ 3 Faculty of Civil Engineering Osijek, University of Osijek, Department for Materials and Structures, \\ Drinska 16a, HR - 31000, Osijek, Croatia. E-mail: draganic@gfos.hr
}

\section{Introduction}

Effects of in-plane and out-of-plane loading are generally observed separately $[1,2]$ but recent investigations [3] are trying to combine the influence of in-plane damage on out-of-plane strength. In this paper, out-of-plane effects caused by in-plane loading are observed trough digital image correlation.

\section{Experimental investigation}

Test setup, model description, and behaviour of tested models under in-plane loading can be found [1].

This paper presents an extension of previously published results, providing unique insight into out-of-plane behaviour of tested models caused by in-plane loading.

\subsection{In-plane behaviour}

Response of tested models was evaluated according to limit states. Three limit states were considered based on a certain damage mode and overall global behavior (Fig. 1) [5].

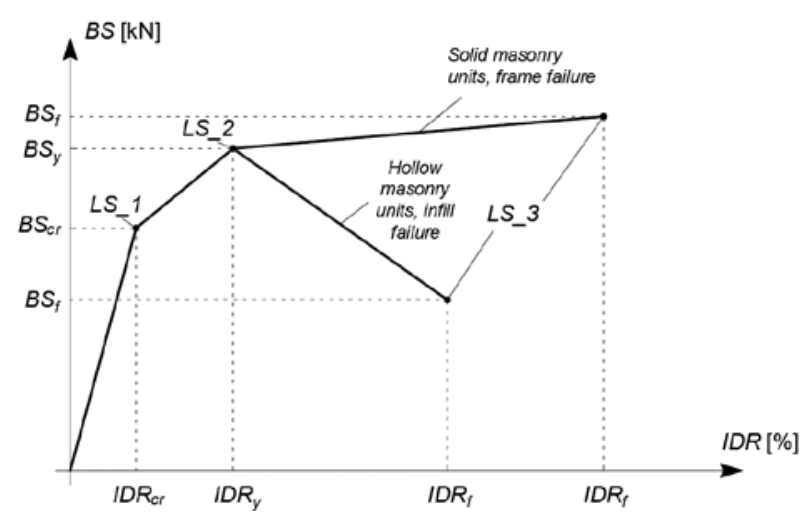

Fig. 1. Backbone curves and limits states of tested models.

\subsection{Out-of-plane deformations}

Out-of-plane deformations were observed in terms of displacement mode and only qualitative representation is given. It was observed that displacement mode was highly influenced by masonry unit robustness. Shift from plate like to rigid body behaviour of infill walls was related to masonry unit robustness. In the range of small inplane deformations, out-of-plane effects were related to imperfections. When a certain in-plane limit state was reached, out-of-plain deformations mode changes accordingly (Fig. 2 and Fig. 3). Only masonry infill type was considered while frame properties were constant.

\section{Conclusions and recommendations}

Out-of-plane deformation mode of masonry infill caused by in-plane loading was investigated based on conducted experimental research on models with varied masonry unit robustness and frame properties. Conclusions were drawn as follows:

- masonry unit robustness played a major role in terms of both in-plane and out-ofplane behaviour,

- masonry infills constructed of solid clay units exhibited plate like behaviour, characterized by inflection points,

- masonry infills made of hollow clay units behaved in a rigid body fashion,

- frame properties influenced out-of-plain behavior only in case of infills made of hollow clay units,

- out-of-plane deformations caused by inplane loading are to be taken in account 


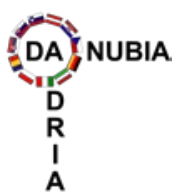

34th Danubia-Adria Symposium on Advances in Experimental Mechanics

University of Trieste, Italy, 2017 when coupled actions (in and out-of-plane loading condition) are considered.

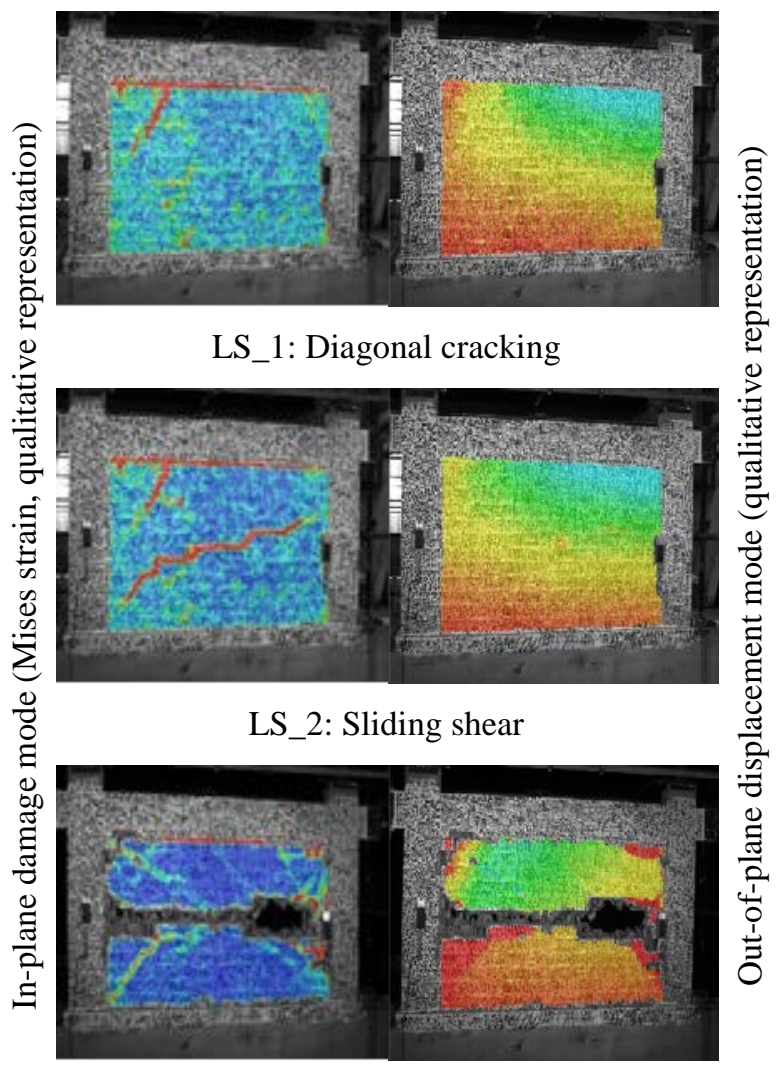

LS_3: Corner crushing

Fig. 2. In-plane damage and out-of-plane displacement mode for sample $\mathrm{O} 4 \_b p m$.

\section{Acknowledgements}

Research presented in this paper is a part of the research project "Frame-masonry for modelling and standardization" No. IP-11-2013-3013, funded by the Croatian Science Foundation and its support is gratefully acknowledged.

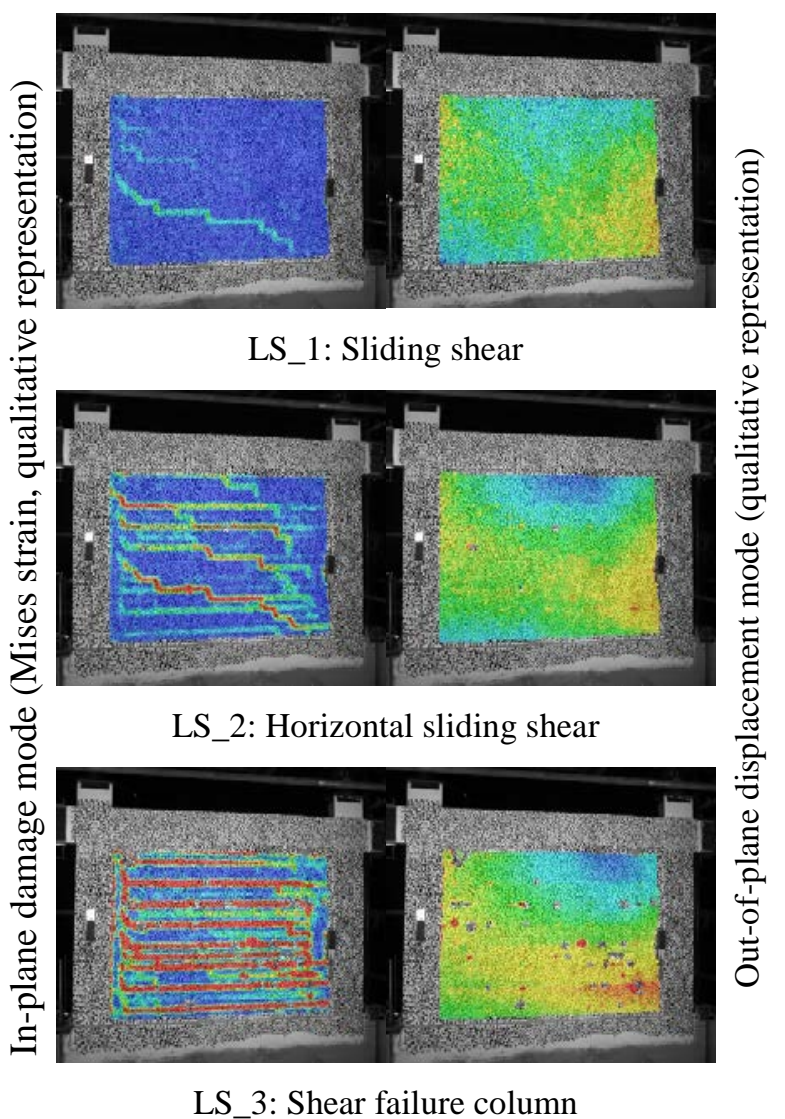

Fig. 3. In-plane damage and out-of-plane displacement mode for sample O4_cpm.

\section{References}

[1] Gazić, G., Sigmund, V., Cyclic testing of single-span weak frames with masonry infill, Građevinar, 8, 617-633, 2016.

[2] Abrams, D. P., Angel, R., Uzarski, J., Out-ofPlane Strength of Unreinforced Masonry infill Panels, Earthquake Spectra, 12, 825-844, 1996.

[3] Furtado, A., Rodrigues, H., Arede, A., Varum, H., Experimental evaluation of out-of-plane capacity of masonry infill walls, Engineering Structures, 111, 48-63, 2016. 